\title{
EL DELITO DE TRÁFICO DE MIGRANTES. UN ANÁLISIS COMPARADO A LOS TIPOS PENALES ESPAÑOL Y GHILENO*
}

\author{
THE CRIME OF MIGRANT SMUGGLING. A COMPARATIVE ANALYSIS \\ OF THE SPANISH AND CHILEAN CRIMINAL OFFENSES
}

\section{Sebastián SALINERO ECHEVERRÍA**}

RESUMEN: El presente trabajo realiza un análisis jurídico comparado del delito de tráfico de migrantes, previsto y sancionado en el artículo 318 Bis y 411 Bis de los códigos penales español y chileno, respectivamente. En particular, se atiende a poder establecer el bien jurídico tutelado por esta figura, inclinándose a por qué se trata de un delito pluriofensivo en el que están en juego intereses individuales y colectivos. Por otro lado, se ocupa de poder delimitar el sujeto pasivo que es protegido por la norma penal. Finalmente, se reflexiona sobre los verbos rectores de la conducta criminal.

Palabras clave: tráfico de migrantes, bien jurídico tutelado, pluriofensividad, sujeto pasivo, verbos rectores, fines de lucro.
ABSTRACT: This work represents a legal comparative analysis of the crime of migrant smuggling, set forth and sanctioned in Articles 318 Bis and 411 Bis of the Spanish and Chilean criminal codes, respectively. In particular, we address the possibility to establish this figure's protected legal interest, thus leaning to why it would be a multi-offense crime, in which both individual and collective interests are at stake. On the other hand, we address the possibility to define the victim protected by the regulation. Finally, we contemplate the criminal conduct's ruling verb.

Keyzeords: Migrant Smuggling, Protected Legal Interest, Multi-offense Crime, Victim, Ruling Verbs, Profit Motive.

* Artículo recibido el 9 de agosto de 2017 y aceptado para su publicación el 7 de febrero de 2019.

** ORCID: 0000-0003-4988-8357. Doctor en derecho por la Universidad de Lérida. Profesor investigador en la Universidad de Talca (Chile). Agradezco la valiosa colaboración de los becarios del Centro de Estudios de Derecho Penal: Sebastián Galleguillos, Patricio Acuña, Alejandra Bustos y Karyn Anléu. Correo electrónico: ssalinero@utalca.cl.

Boletín Mexicano de Derecho Comparado, nueva serie, año LI, núm. 155, mayo-agosto de 2019, pp. 1015-1045. 
SUMARIO: I. Introducción. II. El bien jurídico protegido en el delito de tráfico de migrantes. III. El sujeto pasivo de la conducta incriminada. IV. Los verbos rectores de la conducta punible. V. Conclusión. VI. Referencias bibliográficas.

\section{INTRODUCGIÓN}

El delito de tráfico de migrantes tiene un origen de más larga data en el caso español que en el chileno. Con la aprobación del Código Penal español de 1995, denominado Código penal de la democracia, surge el delito previsto en el artículo 313.1 para castigar el favorecimiento de la inmigración clandestina de trabajadores a España. Luego, con la dictación de la Ley Orgánica 4/2000, del 11 de enero, y frente a las lagunas punitivas que generaba el precepto legal original, ${ }^{1}$ se crea el delito para sancionar el tráfico de inmigrantes en su artículo 318 bis. Como no existía una ubicación adecuada conforme a su naturaleza jurídica, este ilícito se localiza bajo un nuevo título denominado "Delitos contra los derechos de los ciudadanos extranjeros" (Pomares Cintas 2015, 2 y 3). Este delito de colaboración a la inmigración ilegal fue objeto de múltiples modificaciones, las que respondieron a la necesidad española de cumplir con las diversas directrices comunitarias emanadas del Consejo Europeo de Tampere, sobre la creación de un espacio de libertad, seguridad y justicia, de octubre de 1999, ${ }^{2}$ y los compromisos adquiridos en la Convención contra la De-

1 Para un detalle del problema que se generaba, véase Pomares Cintas (2015, 1-20).

2 El delito de tráfico de migrantes tiene su origen en la Ley Orgánica 4/2000, del 11 de enero, y en un sola disposición penal, se sancionaba con las penas de prisión de 6 meses a 3 años y multa de 6 a 12 meses, a "los que promuevan, favorezcan o faciliten el tráfico ilegal de personas desde, en tránsito o con destino a España", tipo que era el básico-residual y que se agravaba en mayor o menor medida en función de diversos criterios: ánimo de lucro, empleo de medios comisivos que, limitan o anulan la capacidad de autodeterminación o decisión de la víctima (violencia, intimidación, engaño o abuso de una situación de necesidad), minoría de edad, puesta en peligro de la vida, la salud o la integridad de las personas, u otras circunstancias relativas al autor —abuso de su condición pública o pertenencia a una organización-.

Posteriormente, se erige la primera modificación por Ley Orgánica 11/2003, del 29 de septiembre, de medidas concretas en materia de seguridad ciudadana, violencia doméstica e integración social de los extranjeros, la que no buscaba otra cosa que ampliar el tipo penal y agravarlo. En concreto, la reforma aumentó el marco penal para los que colaboren en la entrada, circulación y estancia irregulares de extranjeros "sean o no trabajadores". Esto no sólo implicó un incremento punitivo, sino que, también, se amplió ilimitadamente 
lincuencia Organizada Transnacional, aprobada el 15 de noviembre de 2000, también conocida como Convención de Palermo, y sus protocolos complementarios (Protocolo para prevenir, reprimir y sancionar la trata de personas, especialmente mujeres y niños, y Protocolo contra el tráfico ilícito de migrantes por tierra, mar y aire), ratificados por España el 21 de febrero de 2002. ${ }^{3}$ La última modificación se realizó mediante Ley Orgánica 1/2015, del 30 de marzo, la cual persiguió, entre otras cosas, tener una mayor claridad a la hora de delimitar las conductas punibles, conforme a las directrices comunitarias (Directiva 2002/90/CE, Decisión Marco 2002/946/JAI), y corregir la desproporcionada reacción punitiva de este delito y la trata de personas, esta última que a todas luces importa un mayor injusto que el tráfico (véase la exposición de motivos de la ley).

el tipo básico, abarcando conductas de colaboración "directa o indirecta" en el tráfico ilegal o la "inmigración clandestina" de personas. Con ello, se produce una distorsión entre los artículos 313.1 y 318 bis.

Una nueva reforma se presentó en 2007, mediante la Ley Orgánica 13/2007, del 19 de noviembre, ampliando nuevamente el tipo básico, para describir que la conducta incriminada se extendía a que el destino del inmigrante ilegal no era sólo España, sino cualquier país de la Unión Europea. Ello se consigue sumando a la expresión "desde, en tránsito o con destino a España", una nueva voz "o con destino a otro país de la Unión Europea".

Nuevamente se presenta otra modificación en 2010, por medio de Ley Orgánica 5/2010, del 22 de junio, la cual vino a terminar el conflicto que, hasta ese momento, existía entre el solapamiento de la norma de los artículos 313.1 y 318 bis; también se termina con la confusión de regular en una misma norma penal dos institutos jurídicos diferentes, como son la trata de personas y el tráfico de migrantes, y finalmente se pretendió dar cumplimiento a los compromisos internacionales existentes, tanto a nivel regional europeo como a nivel internacional. Por ello, la reforma creó el delito de trata de seres humanos en una disposición normativa distinta, en el artículo 177 bis, basado en la ausencia de consentimiento de la víctima y una finalidad de explotación, y, por otro lado, mantuvo en el artículo 318-bis el tráfico de migrantes. Sin embargo, se podría indicar como lo ha sostenido la doctrina, que la reforma empeoró el conflicto terminológico que existía entre ambas disposiciones. Por ejemplo, entre otros errores, se mantuvo los medios comisivos propios de la trata (violencia, intimidación, engaño, o abuso de una situación de superioridad o de especial vulnerabilidad de la víctima) en el tráfico de migrantes. Tampoco se cumplieron con los compromisos internacionales, particularmente de ajustar la tipificación nacional a aquellos, se sigue equiparando la tentativa con la consumación y la autoría con las formas de participación. Asimismo, las penas previstas excedían de los límites impuestos por las normas europeas (Decisión Marco 2002/946/JAI). Para mayor detalle de las reformas y contenidos de éstas, véase Pomares Cintas (2015, 1-20).

3 Estos instrumentos, entre otras cosas, se caracterizan por castigar la delincuencia organizada para cometer los delitos de tráfico ilícito de migrantes y la trata de personas respectivamente. 
El Título XV Bis del Código Penal español, que lleva por nombre "Delitos contra los derechos de los ciudadanos extranjeros", contempla un único artículo, el 318 bis, que dispone lo siguiente:

1. El que intencionadamente ayude a una persona que no sea nacional de un Estado miembro de la Unión Europea a entrar en territorio español o a transitar a través del mismo, de un modo que vulnere la legislación sobre entrada o tránsito de extranjeros, será castigado con una pena de multa de tres a doce meses o prisión de tres meses a un año. Los hechos no serán punibles cuando el objetivo perseguido por el autor fuere únicamente prestar ayuda humanitaria a la persona de que se trate. Si los hechos se hubieran cometido con ánimo de lucro se impondrá la pena en su mitad superior.

2. El que intencionadamente ayude, con ánimo de lucro, a una persona que no sea nacional de un Estado miembro de la Unión Europea a permanecer en España, vulnerando la legislación sobre estancia de extranjeros será castigado con una pena de multa de tres a doce meses o prisión de tres meses a un año.

3. Los hechos a que se refiere el apartado 1 de este artículo serán castigados con la pena de prisión de cuatro a ocho años cuando concurra alguna de las circunstancias siguientes: a) Cuando los hechos se hubieran cometido en el seno de una organización que se dedicare a la realización de tales actividades. Cuando se trate de los jefes, administradores o encargados de dichas organizaciones o asociaciones, se les aplicará la pena en su mitad superior, que podrá elevarse a la inmediatamente superior en grado. b) Cuando se hubiera puesto en peligro la vida de las personas objeto de la infracción, o se hubiera creado el peligro de causación de lesiones graves.

4. En las mismas penas del párrafo anterior y además en la de inhabilitación absoluta de seis a doce años, incurrirán los que realicen los hechos prevaliéndose de su condición de autoridad, agente de ésta o funcionario público.

5. Cuando de acuerdo con lo establecido en el artículo 31 bis una persona jurídica sea responsable de los delitos recogidos en este Título, se le impondrá la pena de multa de dos a cinco años, o la del triple al quíntuple del beneficio obtenido si la cantidad resultante fuese más elevada. Atendidas las reglas establecidas en el artículo 66 bis, los jueces y tribunales podrán asimismo imponer las penas recogidas en las letras b) a g) del apartado 7 del artículo 33.

6. Los tribunales, teniendo en cuenta la gravedad del hecho y sus circunstancias, las condiciones del culpable y la finalidad perseguida por éste, podrán imponer la pena inferior en un grado a la respectivamente señalada. 
Por otra parte, en el caso chileno el delito de tráfico de migrantes es un ilícito novísimo y su inclusión respondió a la necesidad de cumplir también con los compromisos internacionales (Biblioteca del Congreso Nacional de Chile 2011), ${ }_{4}^{4}$ más concretamente con la Convención de Palermo. ${ }^{5}$ Con ella, como principal fuente jurídica, ${ }^{6}$ se dictó en abril de 2011 la Ley 20.507 que tipificó los delitos de tráfico ilícito de migrantes y la trata de personas, estableciéndose normas para su prevención y más efectiva persecución penal. ${ }^{7}$

Las principales modificaciones introducidas por esta ley fueron, por una parte, la derogación del artículo 367 bis del Código Penal chileno que sancionaba la "trata de blancas" y, por otra, la incorporación de dos

4 Conforme se señala en la exposición de motivos de la ley núm. 20.507, el objetivo fue poner a Chile al día en sus obligaciones internacionales, estableciendo los medios institucionales, tanto normativos y de políticas públicas preventivas, para combatir esta fenomenología delictiva.

5 La Convención y sus Protocolos fueron aprobados por el Congreso Nacional, según consta en los oficios núm. 4.686, del 4 de diciembre de 2003; 5.116 y 5.117 del 19 de agosto de 2004, respectivamente, de la Honorable Cámara de Diputados; los Instrumentos de Ratificación respectivos se depositaron ante el secretario general de la Organización de las Naciones Unidas el 29 de noviembre de 2004. Por Decreto núm. 342, del Ministerio de Relaciones Exteriores, se Promulga la Convención de las Naciones Unidas contra la delincuencia organizada transnacional y sus protocolos contra el tráfico ilícito de migrantes por tierra, mar y aire y para prevenir, reprimir y sancionar la trata de personas, especialmente mujeres y niños. Diario Oficial, núm. 38.088, Santiago, Chile, del 16 de febrero de 2005.

6 También son fuentes relevantes de esta nueva institucionalidad la Convención de los Derechos del Niño, la cual ordena a los Estados parte en su artículo 11: "Adoptar medidas para luchar contra los traslados ilícitos de niños al extranjero y la retención ilícita de niños en el extranjero", y artículo 32, que obliga a: "Reconocer el derecho del niño a estar protegido contra la explotación económica, y contra el desempeño de cualquier trabajo que pueda ser peligroso o entorpecer su educación, o que sea nocivo para su salud o para su desarrollo físico, mental, espiritual, moral o social". Otra fuente por destacar es la Convención Internacional sobre la Protección de los Derechos de todos los Trabajadores Migratorios y de sus familiares, que es un tratado de la ONU, adoptada en diciembre de 1990 y ratificada por Chile en 2005, la cual prohíbe "la aplicación de torturas o tratos o penas crueles, inhumanos o degradantes a los trabajadores extranjeros, así como, su sometimiento a esclavitud o servidumbre".

7 La ley fue promulgada el 1o. y publicada el 8 de abril de 2011. Tuvo su origen en una moción de la diputada María Antonieta Saa, del 5 de enero de 2005, titulada "Proyecto de ley que tipifica el delito de tráfico de niños y de personas adultas y establece normas para su prevención y más efectiva persecución criminal". 
nuevos tipos penales como señala su epígrafe. Estos se encuentran agrupados en el nuevo párrafo 5 bis titulado "De los delitos de tráfico ilícito de migrantes y trata de personas", los que se incorporan en los artículos 411 bis, 411 ter y 411 quáter. Además de crear estos nuevos ilícitos, la ley introduce una serie de modificaciones que escapan al objetivo de este trabajo y tienen relación, en general, con incorporar nuevas técnicas de política criminal para hacer más efectiva la persecución penal de estos delitos. ${ }^{8}$

El delito de tráfico de migrantes, previsto en el artículo 411 bis del Código Penal chileno, dispone lo siguiente:

Tráfico de migrantes. El que con ánimo de lucro facilite o promueva la entrada ilegal al país de una persona que no sea nacional o residente, será castigado con reclusión menor en su grado medio a máximo y multa de cincuenta a cien unidades tributarias mensuales.

La pena señalada en el inciso anterior se aplicará en su grado máximo si se pusiere en peligro la integridad física o salud del afectado.

Si se pusiere en peligro la vida del afectado o si éste fuere menor de edad, la pena señalada en el inciso anterior se aumentará en un grado.

Las mismas penas de los incisos anteriores, junto con la de inhabilitación absoluta temporal para cargos u oficios públicos en su grado máximo, se impondrá si el hecho fuere ejecutado, aun sin ánimo de lucro, por un funciona-

8 Entre otras cosas, se introduce el artículo 89 bis, que faculta a los extranjeros condenados por alguno de los delitos de tráfico y/o trata, a cumplir en el país de origen las penas privativas de libertad que les hubieren sido impuestas. También se agrega el artículo 411 octies que dota de nuevas técnicas investigativas, reemplazando las que antes estaban consideradas en el artículo 369 ter inciso 1. Por su parte, en la línea de una política criminal eficiente, se incorpora la figura del cooperador eficaz en el artículo 411 sexies. A su vez, el artículo 411 septies contiene una regla especial para la determinación de la reincidencia específica.

Además del Código Penal, se realizan una serie de modificaciones a otros cuerpos legales, con la finalidad de articular una mejor persecución de estos nuevos tipos penales. Se modifica el artículo 5o. del Decreto Ley 2.460, Ley Orgánica de la Policía de Investigaciones de Chile, otorgando a esta policía la facultad de adoptar todas las medidas conducentes para asegurar la correcta identificación de las personas que salen e ingresan del país, la validez y autenticidad de sus documentos de viaje y la libre voluntad de las personas de ingresar o salir de él. También se modifica la Ley de Extranjería, Decreto Ley 1.094, incorporándose un artículo 33 bis, que permite a las víctimas del delito previsto en el artículo 411 quáter del Código Penal, que no sean nacionales o residentes permanentes en el país, presentar una solicitud de autorización de una residencia temporal, por un periodo mínimo de seis meses. 
rio público en el desempeño de su cargo o abusando de él. Para estos efectos se estará a lo dispuesto en el artículo 260.

Desde una mirada a las tipificaciones española y chilena se pueden advertir ciertas similitudes. Sin embargo, sólo me centraré en algunas de ellas. Como propuesta de trabajo, con base en un análisis jurídico penal, me abocaré como primer objetivo a poder establecer el bien jurídico tutelado en estas figuras; en segundo término, a poder determinar la singularidad del sujeto pasivo que es protegido por la norma penal, y finalmente reflexionar sobre los verbos rectores de la conducta incriminada.

Con base en lo anterior, a fin de cuentas, propongo, basado en una crítica de la tesis tradicional dominante, delimitar de modo distinto el bien jurídico protegido - el cual se sostiene de mejor manera en el caso chileno que en el español- y, a partir de dicha interpretación, configurar el sujeto pasivo de los delitos y sus conductas típicas.

\section{EL BIEN JURÍDICO PROTEGIDO EN EL DELITO DE TRÁFICO DE MIGRANTES}

La importancia de determinar el interés jurídicamente protegido por la norma penal no sólo cumple un rol garantista, limitador de la punibilidad estatal, sino que, proporciona los criterios de enjuiciamiento que hay que desarrollar en materia jurídica y que el legislador y el aplicador del derecho tienen que consultar a la hora de crear e interpretar cada norma en concreto (Roxin 2007, 58). Saber cuál es el interés social que tutela la norma, no sólo contribuirá a determinar si en el caso concreto existe la necesaria antijuridicidad material, sino también, entre otras cosas, conocer las formas de aparición del delito y como presupuesto necesario para resolver cuestiones concursales, entre otras importantes cuestiones (Matus Acuña 2011, 11).

\section{El caso español}

Desde su aparición, la doctrina española debatió profusamente sobre el bien jurídico protegido en el delito de tráfico de migrantes. Sin embargo, hoy la cuestión es un tanto más pacífica, pues existe un consenso generalizado de que el interés en controlar los flujos migratorios es el objeto tutelado. 
En un comienzo, previo a la reforma impetrada por la Ley Orgánica 5/2010, del 22 de junio, donde el delito en comento era normativamente regulado en la misma disposición que el delito de trata de personas, ${ }^{9}$ la dispersión de posturas se decantó por una serie de intereses que podían ser afectados, tanto de naturaleza individual como colectiva (vida, libertad, salud, integridad, dignidad, control estatal de los flujos migratorios y los derechos de los ciudadanos extranjeros), sumado a la cuestión de determinar si se tutelaba sólo un bien jurídico o bien se trataba de un delito de carácter pluriofensivo. ${ }^{10}$

Con la actual legislación penal española - y más precisamente a partir de la reforma de 2010 - ${ }^{11}$ la doctrina mayoritariamente ha entendido al control de los flujos migratorios como el valor social que protege este delito (Villacampa Estiarte 2016, 752; Gómez López y Muñoz Sánchez

9 Previo a la reforma de 2010, se solapaban dos delitos en la misma norma del artículo 318 bis, como son los que englobaban conductas de tráfico y de trata de personas. Por ello, independiente de su ubicación sistemática, la doctrina española declaró prácticamente de manera transversal que se trataba de figuras distintas y que su tratamiento unificado generaba confusión y desconcierto (véase Daunis Rodríguez 2013, 10; Pérez Alonso 2008, 218; Pomares Cintas 2015, 7).

10 La doctrina que indicaba que se protegía sólo un bien jurídico, se dividía entre los que se pronunciaban por la lesión de los derechos de los ciudadanos extranjeros y, por otro lado, los que indicaban que lo perturbado era el interés estatal en controlar y ordenar los flujos migratorios. A propósito de los derechos de los ciudadanos extranjeros se agrupan: Rodríguez Mesa (2001, 55 y ss.); Serrano-Piedecasas (2002, 331 y ss.). Con relación al control de los flujos migratorios encontramos a: Ortubay Fuentes (2002, 447 y ss.); Díaz y García Conlledo (2007, 205); Rodríguez Montañés (2001, 1738 y ss.); Pérez Alonso (2008, 356 y ss.); Daunis Rodríguez (2009, 70 y ss.). Aunque el autor repara que “...no nos encontramos ante un bien jurídico penal, sino ante una prohibición administrativa que se ha elevado a la categoría de ilícito penal". Por otro lado, los autores que indicaban que se trataba de un tipo pluriofensivo consideraban que se lesionaba mediatamente tanto los derechos individuales de los inmigrantes como colectivos, e inmediatamente el control de los flujos migratorios como un aspecto concreto del orden socioeconómico, sin embargo, otros autores reconocen como protegida la propia dignidad de estas personas. Véase Rodríguez Montañés (2001, 1738); García España y Rodríguez Candela (2002, 732 y ss.) De manera similar se manifiesta Martínez-Buján Pérez (2016, 500); Laurenzo Copello (2003, 63-94).

11 La exposición de motivos de la citada ley disponía que con el delito en comento se protegía un bien jurídico colectivo, el cuál era el interés del Estado en el control de los flujos migratorios (Villacampa Estiarte 2011, 1211 y ss.). Con la modificación impetrada por la LO 1/2015, del 30 de marzo, la exposición de motivos del delito de tráfico de migrantes, previsto en el artículo 318 bis, nada dice en torno al bien jurídico tutelado.

Esta obra está bajo una Licencia Creative Commons

Atribución-NoComercial-SinDerivar 4.0 Internacional, IIJ-UNAM.

Boletín Mexicano de Derecho Comparado, núm. 155, mayo-agosto de 2019, pp. 1015-1045. 
2017, 228 y ss.; Lafont Nicuesa n.d., 10 y ss.; Daunis Rodríguez 2017, 452 y ss.; Monge Fernández 2017, 142; Santana Vega 2015, 1117 y ss.; Muñoz Conde 2017, 321 y ss.). ${ }^{12}$ Interés social que la jurisprudencia de los tribunales superiores de justicia ha venido reiterando de manera sistemática, a lo menos desde la última reforma legal (LO 1/ 2015). ${ }^{13}$

12 Indica que, aunque a primera vista el bien jurídico protegido parecen ser los derechos de los ciudadanos extranjeros, el verdadero objeto es más bien el conjunto de disposiciones administrativas que regulan los derechos y libertades de los extranjeros en España, principalmente la Ley de Extranjería española, que contiene básicamente restricciones de estos derechos (con ciertas críticas también Pomares Cintas 2015, 11 y ss.; Iglesias Skulj 2015, 942).

13 Previo a la reforma operada por LO 1/2015, del 30 de marzo, el Tribunal Supremo Español si bien estaba conteste en que el control de los flujos migratorios era el interés relevante, requería además de este incumplimiento de la normativa administrativa en materia de extranjería, una afectación negativa relevante, actual o seriamente probable, de los derechos del ciudadano extranjero. La STS 646/2015, del 20 de octubre, realiza un análisis de la doctrina jurisprudencial referida a la anterior redacción del artículo 318 bis, poniendo de relieve que en dicha doctrina jurisprudencial se hacía especial incidencia en la necesidad de que "no basta con acreditar cualquier infracción de la normativa administrativa sobre la materia, sino que la referencia a la ilegalidad del tráfico o a la clandestinidad suponen el empleo por parte del autor de alguna clase de artificio orientado a burlar los controles legales establecidos en el ámbito de la inmigración, o con carácter general del tránsito de personas de unos países a otros" o bien de "que ha de tratarse de una acción que, desde una observación objetiva, y en relación a su propia configuración, aparezca dotada de una mínima posibilidad de afectar negativamente al bien jurídico. Desde la perspectiva relacionada con el bien jurídico, aun cuando se entienda, como hace un sector doctrinal, que el delito trata de proteger el control sobre los flujos migratorios, su ubicación sistemática en un nuevo Título XV bis bajo la rúbrica de los delitos contra los derechos de los ciudadanos extranjeros, impide prescindir de una suficiente consideración a este bien jurídico, por lo que será preciso que las circunstancias que rodean la conducta permitan apreciar la existencia de alguna clase de riesgo relevante para ese bien protegido como consecuencia del acto de favorecimiento del tráfico ilegal o de la inmigración clandestina...". En consecuencia, la conducta típica del artículo 318 bis no se corresponde mecánicamente con el mero incumplimiento de la normativa administrativa en materia de extranjería. El referido precepto exige una afectación negativa relevante, actual o seriamente probable, de los derechos del ciudadano extranjero o, en su caso, que "no es posible elevar a la categoría de delito, y además severamente castigado, conductas que en la legislación de extranjería vienen configuradas como una mera infracción administrativa de manera que el interés del Estado en el control de los flujos migratorios, ya protegido mediante la acción administrativa, solo encuentra protección penal si los derechos de los ciudadanos extranjeros se ven, seria y negativamente, afectados por la conducta, sea de modo actual y efectivo o al menos ante un riesgo de concreción altamente probable". 
Por ejemplo, la STS núm. 536/2016, del 17 de junio, así lo ratifica "...todo ello con la finalidad de respetar la unidad del Derecho Europeo en una materia de interés común, como es el control de los flujos migratorios" y la STS núm. 512/2016, del 10 de junio, conforme a la STS núm. 482/2016, del 3 de junio "sancionándose esencialmente la vulneración de la normativa reguladora de la entrada, tránsito o permanencia de extranjeros en el territorio de la Unión (Directiva 2002/90/CE, del 28 de noviembre, y Decisión Marco 2002/946/JAI)".

Señalando también el Tribunal Supremo, a modo de resolver cualquier duda y evitar interpretaciones forzadas, que los derechos de los ciudadanos extranjeros sólo se protegen de manera colateral en el caso de grave peligro para la vida o integridad física.

STS núm. 536/2016, del 17 de junio: "Y solo en los supuestos agravados de puesta en peligro de la vida o la integridad del inmigrante, se atiende además al bien jurídico pregonado en la rúbrica del título, como delitos contra los derechos de los ciudadanos extranjeros", y STS núm. 482/2016, del 3 de junio “....sin perjuicio de amparar también los derechos de los ciudadanos extranjeros de un modo más colateral".

A modo de epílogo, hay que señalar que, previo a la reforma de 2015, la discusión en torno al bien jurídico protegido en este delito y las intenciones de la doctrina en justificarlo a la luz de los derechos de los ciudadanos extranjeros tenía aparentemente una respuesta dual: por una parte, agregar requisitos de legitimidad de la pena que, recordemos, era bastante desproporcionada al injusto ${ }^{14} \mathrm{y}$, por otra parte, devolver acertadamente cierto estatus al derecho penal de ser un recurso de ultima ratio que no está para cuestiones o infracciones administrativas (Pomares Cintas 2015, 15). Todo sin perjuicio del errado tratamiento penal unificado - antes de la reforma de 2010 - que tenía la trata (donde no mediaba consentimiento de la víctima) y el tráfico de migrantes (el inmigrante consiente), el cual generaba confusión y contribuyó de buena manera a la dispersión de posturas relatadas previamente (Gómez López y Muñoz Sánchez 2017, 226 y ss.).

14 Situación que incluso quedó plasmada en la exposición de motivos de la LO 1/2015, del 30 de marzo.

Esta obra está bajo una Licencia Creative Commons

Atribución-NoComercial-SinDerivar 4.0 Internacional, IIJ-UNAM.

Boletín Mexicano de Derecho Comparado, núm. 155, mayo-agosto de 2019, pp. 1015-1045. 


\section{El caso chileno}

En el ámbito chileno, pese a la novedad que supone una disposición penal que sanciona el tráfico ilícito de migrantes, la doctrina se encuentra dividida, pero la mayoría concuerda con que se trata de un delito contra el Estado, una violación a las leyes migratorias (Biblioteca del Congreso Nacional de Chile 2011, 46). ${ }^{15}$ Posiblemente, la razón de aquello es que la doctrina española ha servido de precedente para ello, lo que se nota en las fuentes utilizadas por los pocos trabajos que sobre el tema existen en el caso chileno.

Algunos como Matus Acuña y Ramírez (2014, 195; véase también Laurenzo Copello 2003; Soto Donoso 2009, 172) han manifestado que lo protegido en el delito de tráfico de migrantes no es sólo la afectación de intereses de la víctima - inmigrante-, sino que principalmente es la vulneración de las normas migratorias de los Estados. En forma similar, restando el carácter pluriofensivo al delito, otros autores han indicado que el único interés que subyace a la norma es la tutela del sistema migratorio del Estado (Gajardo Orellana y Torres Figueroa 201 1, 239; véase también Carnevali 2017, 241).

En una postura disidente a que el control de los flujos migratorios sea el objeto de tutela, se manifiestan Mardones y Fernández (2015, 14), indicando que además de tratarse de un delito de peligro abstracto, aquí estaríamos frente a un delito que protege la dignidad de las personas. Ésta se ve afectada en el momento que se ponen en marcha procesos de despersonalización, es decir, cuando la persona es asumida como una cosa, un objeto o mercancía (cosificación), anulándose su característica de seres libres. ${ }^{16}$

Por otra parte, aludiendo un carácter pluriofensivo a este delito se manifiesta Maldonado (2012, 103), en su opinión, se encontrarían comprometidos intereses individuales y colectivos. Se decanta porque existe un atentado a la generalidad de los derechos de los extranjeros, por existir

15 La Ley núm. 20.507 tipifica los delitos de tráfico ilícito de migrantes y trata de personas y establece normas para su prevención y más efectiva persecución criminal.

16 No obstante considerar una afectación a la dignidad humana en el tráfico de migrantes, estiman manejar una interpretación restrictiva dirigida a la tutela de la explotación del extranjero ilegal, por cuanto una interpretación distinta transformaría el bien jurídico en una afectación al principio de determinación del mandato legal. 
una reducida posibilidad de obtener amparo o protección jurídica o social. Se trataría de una situación fáctica de menor acceso efectivo al ejercicio de derechos, por la especial situación de vulnerabilidad en la que se encuentra el extranjero.

La jurisprudencia, por su parte, es escasa y no está representada en sentencias de tribunales superiores, sino solamente inferiores (tribunales orales y de garantía), los que se manifiestan en la línea de que el control de los flujos migratorios sería el interés que subyace al delito. ${ }^{17}$ Pero esta visión no es generalizada, puesto que algún tribunal sostiene que se trata de un delito pluriofensivo que protege tanto la seguridad individual como la libertad personal, entendidos estos como derechos que emanan de la dignidad de la persona, ${ }^{18} \mathrm{y}$ otro sostiene que además del interés estatal, de manera más relevante, se protege la dignidad humana. ${ }^{19}$

\section{Crítica a la tesis mayoritaria y presentación de una propuesta alternativa para el caso chileno}

La tesis basada en la defensa del sistema migratorio, de orden y control de los flujos, merece severas críticas, tanto en su aspecto sustantivo como en el orgánico sistemático.

Con respecto al aspecto sustantivo, en España como en Chile existen ordenamientos jurídicos especiales, de carácter administrativo, que de manera exclusiva y excluyente se ocupan del control migratorio dentro de las fronteras de esos Estados. En España, existe la Ley Orgánica 4/2000, del 11 de enero, sobre derechos y libertades de los extranjeros en España y su integración social, y en Chile, el Decreto Ley 1094, del 14 julio de 1975, que establece normas sobre extranjeros en Chile. Ambos cuerpos normativos contienen disposiciones que sancionan al extranjero, como a otras

17 Cuarto Tribunal Oral en lo Penal de Santiago, sentencia del 13 de diciembre de 2012, RUC 1001114184-1; Tribunal Oral en lo Penal de Santa Cruz, sentencia del 12 de marzo de 2013, RUC 1200236968-9; Tribunal del Juicio Oral en lo Penal de Arica, sentencia del 20 de noviembre de 2013, RUC 1300331670-4; Tribunal Oral en lo Penal de Santa Cruz, sentencia del 8 de junio de 2015, RUC 1110028038-K.

18 Tribunal Oral en lo Penal de Arica, sentencia del 16 de marzo de 2016, RUC 1500472364-0.

19 Primer Tribunal Oral en lo Penal de Santiago, del 11 de julio de 2017, RUC 1600660322-3.

Esta obra está bajo una Licencia Creative Commons

Atribución-NoComercial-SinDerivar 4.0 Internacional, IIJ-UNAM.

Boletín Mexicano de Derecho Comparado, núm. 155, mayo-agosto de 2019, pp. 1015-1045. 
personas, en caso de conductas de entrada, permanencia y egreso ilícito al país (véanse artículos 50 y ss. de la LO 4/2000; artículos 68 y siguientes del D.L. núm. 1094). Así, en el evento de existir dos normativas jurídicas - la ley de extranjería de cada país y el código penal respectivo- abocadas a la protección del mismo interés (control de flujos migratorios), se daría la curiosa dicotomía de coexistir en un mismo ordenamiento jurídico dos fuentes que sancionan similares conductas y tutelan el mismo interés social. Frente a ello, hay que preguntarse - y responder negativamente al mismo tiempo - si desde la óptica jurídico penal, las conductas de colaboración a la inmigración ilegal, punibles en ambos Estados, y que además muchas de ellas son ilícitos administrativos (véase artículo lo. del D.L. núm. 1094), son compatibles con el principio de subsidiariedad que erige al derecho penal como último recurso frente a un derecho administrativo menos lesivo. ${ }^{20}$

Otra línea de reproche con carácter sustantivo se presenta en la situación de poder determinar si el sistema migratorio, entendido básicamente como el conocimiento cualitativo (quiénes) y cuantitativo (cuántos) de los extranjeros que ingresan, permanecen y egresan de cada Estado, se configura como interés social que represente la necesaria antijuridicidad material que deba importar un ilícito penal.

Un argumento adicional para criticar el sistema migratorio, como interés digno de protección penal, es de índole orgánico sistemático. Pues, tanto el legislador español como el chileno ubican al delito en un lugar que no hace presagiar ese bien jurídico como objeto de tutela. Así, en el caso español el delito se sitúa en el Título XV Bis, del Libro II del Código Penal, denominado "Delitos contra los derechos de los ciudadanos extranjeros". Con el nombre de ese epígrafe es difícil de sostener que lo tutelado, a lo menos directamente, no sea otra cosa que un derecho de un ciudadano extranjero. A su vez, el Código Penal chileno, sitúa este delito en el párrafo 5 bis, del Título VIII, del Libro II del Código penal, referido a los crímenes y simple delitos contra las personas. De esta forma, se trataría de un delito que afectaría intereses de las personas y no del Estado como de suyo implica el sistema migratorio.

20 De una manera parecida, entre otros, se manifiestan: Villacampa Estiarte (2016, 753 y 754); Pomares Cintas (2015, 18). 
Terminada la crítica, en los siguientes párrafos expondré una propuesta alternativa de bien jurídico protegido en el delito de tráfico de migrantes, pero sólo para el caso chileno. La razón de porqué aplicar a este caso y no al español obedece particularmente a que tanto el legislador como la doctrina jurisprudencial, en la península, ya se decantaron por el bien jurídico control de los flujos migratorios como objeto tutelado. Además, el caso chileno merece un trato especial, pues la pena prevista para el tipo penal residual es bastante grave (hasta cinco años de prisión), lo que amerita un entramado de bien jurídico más complejo, más allá de una falta administrativa.

La tesis que se propone considera que este delito pone en peligro intereses individuales y colectivos de manera simultánea (Roxin 2007, 58). Particularmente, se trataría de los derechos individuales de los extranjeros inmigrantes como víctimas, y el orden público como bien colectivo, cuyo padecimiento corresponde a la sociedad en su conjunto.

La propia Convención de Palermo, a través de su Protocolo complementario, reconoce expresamente que existe una necesidad de dar un trato humano a los migrantes y proteger sus derechos humanos. ${ }^{21}$ Teniendo presente aquello, parece que el tráfico de migrantes se erige como un delito que puede afectar directamente intereses humanos individuales, como serían los derechos de los ciudadanos extranjeros (vida, integridad física, etcétera). ${ }^{22}$

En este sentido, se pueden advertir dos momentos en que estos derechos individuales pudiesen ser afectados. Un primer momento, con la actividad de tráfico propiamente como tal, es decir, cuando los extranjeros son transportados y se puede poner en riesgo su vida, integridad física, salud, u otros bienes jurídicos. La protección de estos bienes tiene un correlato con lo que la evidencia se ha encargado de demostrar. Los valores vida, integridad física y salud del extranjero, son los bienes que son amenazados o lesionados con la actividad de tráfico. Piénsese, verbigracia, en los grandes países receptores de oleadas de inmigrantes, como son Estados

21 Puede consultarse el Preámbulo del Protocolo Contra el Tráfico Ilícito de Migrantes por Tierra, Mar y Aire, que Complementa la Convención de las Naciones Unidas Contra la Delincuencia Organizada Transnacional.

22 Naciones Unidas, desde el Convenio de la Trata, en 1949, se ha preocupado fundamentalmente de la dramática situación de los derechos humanos de las mujeres y niñas (De León Villalba 2003, 114 y ss.). 
Unidos y Europa occidental, y en el modus operandi de las organizaciones criminales que trafican inmigrantes. Generalmente, el tráfico se hace en condiciones inhumanas y poco seguras, como lo constituyen las largas caminatas que deben hacer por el árido y agreste desierto texano o el de Arizona en el caso americano, o a través del paso por las aguas del mediterráneo en embarcaciones deficitarias que naufragan de manera recurrente, ${ }^{23}$ y que ha llevado incluso al Papa Francisco, con acierto, a calificar este mar como un cementerio de inmigrantes (Biles 2014).

En un segundo momento, los derechos de los ciudadanos extranjeros en condiciones de irregularidad se podrían afectar, cuando éstos ingresan al país receptor y permanecen en él. Son los propios extranjeros los que se podrían convertir en víctimas, esto a partir de su propia situación de vulnerabilidad en que podrían verse afectados sus derechos. Se trata de bienes jurídicos individuales de los cuales son propietarios y forman parte de su propio espacio vital, los que en un marco de igualdad jurídica se encuentran libres de abusos por parte de terceros, pero por su especial situación de ilegalidad se verían privados del ejercicio normal (o bien, terceros podrían conculcarlos). Piénsese, por ejemplo, en que los inmigrantes ilegales no pueden acceder a redes básicas de asistencia (hospitales, colegios, etcétera) o son blancos fáciles de la criminalidad. Ello se origina porque su especial situación les impide gozar de los derechos de que son titulares el resto de la población y porque los delitos que los pueden afectar van a formar parte del listado de la cifra negra - delitos no denunciados - por temor a ser expulsados del país por su condición irregular (carecen de tutela judicial efectiva).

En otro aspecto, el delito de tráfico de migrantes amenaza al orden público como interés colectivo, pese a lo alambicado, heterogéneo y discutible que pueda parecer este término. Este es generalmente entendido en términos positivos como la tranquilidad pública, el estado de sosiego general o de paz social (Muñoz Conde 2015, 762), significa el normal y pacífico desenvolvimiento de las actividades ciudadanas (Etcheberry 2010, 261). A esta conclusión se llega luego de un examen del ordenamiento internacional, particularmente la Convención de Palermo y sus

23 En los primeros cuatro meses de 2015, alrededor de 1,700 personas han muerto en el Mediterráneo; 100 veces más que durante el mismo periodo de 2014 (véase Amnistía Internacional, s. d.). 
protocolos complementarios, y a un análisis de las características actuales de los efectos de la inmigración irregulares en los países receptores como se explicará.

En cuanto al instrumento internacional, si bien el Protocolo Contra el Tráfico de Migrantes reconoce que existe una necesidad de dar un trato humano a los migrantes y proteger sus derechos humanos, lo que pudiese evidenciar que se enfocaría únicamente en intereses individuales de estas personas lo que está tras el delito, no se puede pasar por alto que esa misma normativa declara y reconoce que se trata de delitos que ocasionan un "grave perjuicio a los Estados". ${ }^{24} \mathrm{Si}$ bien no se singulariza en qué consisten los perjuicios ni cómo se manifiestan ellos, al respecto es plausible entender que se está haciendo alusión a los efectos del fenómeno y, en este caso, podrían ser los provenientes de una inmigración que es ilegal o irregular.

Ahora, con relación a las características de las migraciones, en estos tiempos, ellas tienen sus raíces en el mismo sistema económico. ${ }^{25}$ El fenómeno de la globalización y la concentración de la riqueza en determinados lugares, unidos a los procesos de dominación económica y de mantenimiento del subdesarrollo en otros lugares, favorecen las migraciones de la fuerza de trabajo al servicio de las exigencias del desarrollo de los países. ${ }^{26}$ Ante esto, se advierten personas que pretenden comenzar un proceso migratorio de manera legal o irregular (dependiendo de los requisitos y exigencias de los países para permitir el ingreso de extranjeros a su te-

24 Véase el Preámbulo del Protocolo Contra el Tráfico Ilícito de Migrantes por Tierra, Mar y Aire, que Complementa la Convención de las Naciones Unidas Contra la Delincuencia Organizada Transnacional.

25 Los mecanismos que ponen en marcha las migraciones, alimentadas por la concentración de la riqueza y medios de producción en determinadas áreas, son: a) económicos: las expectativas de mejor empleo y mayores ingresos; $b$ ) culturales: más oportunidades de educación y promoción; c) de bienestar social: mayores posibilidades de gozar de más y mejores servicios. Pero, ocurre que estos mecanismos, una vez activados, continúan ejerciendo su función impulsora de los movimientos migratorios independientemente de que la coyuntura económica sea de expansión o de recesión (véase Antón Morales 2011, 21).

26 Para Ribas Mateos $(2002,26)$ parece evidente que la desigualdad produzca descontento y violencia en las clases sociales más desfavorecidas y, a su vez, que el mercado requiera y demande seguridad y no inseguridad para su correcto funcionamiento; pero también que el aumento de la brecha entre países ricos y pobres, unido a la globalización de las comunicaciones, produzca el fenómeno de la inmigración, considerada por los expertos como parte de la globalización sumergida (véase también Daunis Rodríguez 2013, 26). 
rritorio), pero siempre con la finalidad de buscar una vida en condiciones mejores a las que tenían en su país de origen.

De esta manera, se puede colegir que las migraciones que hoy cubren el mundo responden, en su gran mayoría, a un objetivo económicolaboral de buscar condiciones personales y familiares con estándares superiores a los que se tenía. Sin embargo, esas loables finalidades podrían ser rupturistas de las condiciones de un determinado mercado o área de la sociedad en el país receptor cuando la migración tiene una naturaleza irregular.

En efecto, cuando los inmigrantes se instalan en el país que los recibe sin cumplir con la normativa administrativa sobre extranjería, es en ese momento en que el orden público se ve amenazado. La inmigración ilegal puede producir efectos perniciosos en el normal desarrollo de las actividades sociales de las naciones que la sostienen, que se manifiestan en la erosión de los niveles de bienestar (económico y social) y en la paz y armonía que deben imperar en la convivencia social. Efectos que se presentan, verbigracia, por la economía sumergida que produce la clandestinidad frente a la imposibilidad de acceso al trabajo formal; la erosión del régimen tributario, sanitario y educacional de un país, al existir sujetos que hacen uso gratuito de los mismos y sin contribuciones de ninguna especie. Más grave, por cierto, son los efectos derivados de la relación social que se podría generar entre nacionales y foráneos. Está estudiado que los autóctonos crean estereotipos de los extraños, lo que lleva posteriormente a actitudes prejuiciosas hacia ellos, más cuando ellos compiten en condiciones de desigualdad con los nacionales, como ocurre frente a la posibilidad del trabajo informal —a un menor costo - para algún sector del mercado. ${ }^{27}$ A ello se suma que ese pensamiento y actitud que en un comienzo fue peyorativo, que solo forma parte de la intimidad del sujeto, a posteriori, se puede exteriorizar en conductas discriminatorias, pudiendo terminar con la conocida xenofobia (Maneri 2010, 34; véase también Dal Lago 2006, 45; Navarro Cardoso 2006, 223-254; Wagman 2002; García España 2001, 81 y 570). Todas actividades que, si bien no se pueden generalizar y pueden ser vistas como sucesos aislados, evidentemente, en caso

27 Un $47.1 \%$ de los encuestados (chilenos) cree que "los inmigrantes les quitan el trabajo a los chilenos" (Instituto Nacional de Derechos Humanos de Chile 2017, 25). 
de ocurrir alteran la paz social o son una afectación o alteración de ese estado de sosiego que debería imperar en la comunidad.

Para el caso chileno, otra razón que sirve para afirmar que la naturaleza de los bienes jurídicos comprometidos en esta figura es el orden público, el cual es de índole histórico-jurídica. Efectivamente, tanto el anteproyecto de Código penal de 2005 que regulaba la inmigración ilegal, y el proyecto de nuevo Código penal de 2014 que castigaba explícitamente el tráfico de migrantes, ${ }^{28}$ contemplaban como bien objeto de tutela "al orden público". ${ }^{29}$ Tampoco está de más decir que el anteproyecto de nuevo Código Penal de 2018, en su Título XII, párrafo 8, explícitamente regula el tráfico de migrantes y reconoce a éste como un delito que afecta el orden público (véase artículo 481 del anteproyecto).

\section{EL SUJETO PASIVO DE LA CONDUCTA INCRIMINADA}

En España es complejo poder hablar de extranjero como sujeto pasivo del delito de tráfico de migrantes, en circunstancias que el bien jurídico protegido es el control de los flujos migratorios (Villacampa 2017, 761). Tal afirmación debería llevar a sostener inequívocamente que tal sujeto es el Estado español y no el extranjero.

Sin perjuicio de lo anterior, la mayoría de la doctrina sigue haciendo referencia al extranjero como sujeto pasivo o también tildándolo como objeto material del delito (Queralt Jiménez 2015, 885; véase también Martínez-Buján Pérez 2016, 500). Por el contrario, Villacampa Estiarte $(2016,761)$ repara en que el sujeto pasivo no puede ser el extranjero.

28 Véase el artículo 501 del Proyecto: "Tráfico de personas. El que con ánimo de lucro para sí o para un tercero facilitare la entrada ilegal al territorio chileno de un extranjero que no sea residente permanente, o la salida ilegal de una persona, será sancionado con prisión de 1 a 5 años y multa. El tribunal estimara la concurrencia de una agravante muy calificada: 1. si se pusiere al migrante en peligro para su persona, 2. si se diere al migrante un trato inhumano o degradante. La tentativa del delito previsto en este artículo es punible. Cuenta como tentativa la elaboración de un documento de viaje o de identidad falso con el propósito de realizar la acción señalada en el inciso primero".

29 El anteproyecto de 2005 regulaba en el párrafo 4 estos delitos, bajo el Título XIV denominados "Delitos contra el orden público"; mientras que el proyecto de 2014, en el párrafo 9 sobre la migración ilegal, regulado en el Título XII que también lleva por nombre "Delitos contra el orden público". 
Hecha la advertencia, debo mencionar que con la modificación impetrada por el legislador de 2015 se abandona en el delito de tráfico de migrantes la histórica referencia al sujeto pasivo como "migrante" o "inmigrante", reemplazándola por el término "persona no nacional de un Estado miembro de la Unión Europea”. Con ello, se pone término a la histórica discusión que en doctrina se generaba, de saber si sólo se refería a los extranjeros como determinaba la rúbrica del título $\mathrm{XV}$ bis, o bien decía relación con todas las personas, cualquiera sea su nacionalidad, incluido los españoles. Problema acentuado por la confusión de encontrarse tratada en la misma disposición legal tanto la inmigración clandestina como la trata de personas. ${ }^{30}$

En la actual legislación, el objeto del delito sólo puede ser un persona que no sea nacional español o de un Estado miembro de la Unión Europea, el que además ha de ser un inmigrante ilegal, porque su entrada o permanencia en España debe vulnerar la legislación administrativa (entrada, tránsito o estancias de extranjeros), lo que implica innegablemente que se debe tratar de un extranjero extracomunitario (Santana Vega 2015, 1119); y, finalmente se requiere que no ostente la condición de trabajador, o estaríamos frente a otro supuesto legal (artículo 311 bis) (Martínez-Buján Pérez 2016, 500).

Para que se dé el tipo básico no es necesario que concurra una pluralidad de extranjeros extracomunitarios. La concurrencia de uno sólo como objeto material del delito tipifica el mismo, incluso aunque haya mediado consentimiento del mismo (Santana Vega 2015, 1119 ; Martínez-Buján Pérez 2016, 500).

Por su parte, el legislador chileno, sin más, se refiere al sujeto pasivo como "persona que no sea nacional o residente", lo que implicaría una definición negativa para comprender como objeto material del delito al extranjero. Empero, el título del precepto utiliza el término "migrante". De ahí que surja la duda de saber a cuál sujeto queda limitada la protección penal.

En atención al problema planteado, el cual no es baladí, ${ }^{31}$ puesto que el concepto extranjero es semánticamente más amplio que el de migrante,

30 Para un examen de las diversas posiciones doctrinarias, véase Rodríguez Mesa (2001, 207 y ss.); Díaz y García Conlledo (2007, 230 y ss.).

31 La interpretación amplia nos llevará al absurdo de entender que el extranjero que 
dándose prácticamente una relación de género a especie, se hace necesario determinar el sujeto y resolver el correcto sentido y alcance que se debiese dar a su respecto.

Para comenzar, la individualidad del sujeto pasivo no puede ser otra que la de un extranjero en consideración a la literalidad de la norma, ${ }^{32}$ por el que se debe entender conforme al Diccionario de la Real Academia Española (el cual comprende tres acepciones): 1) "que es o viene de país de otra soberanía", 2. o bien como alguien "natural de una nación con respecto a los naturales de cualquier otra", y finalmente, 3) la última acepción "toda nación que no es la propia". ${ }^{33}$

Sin embargo, este es un concepto que es extenso todavía, cabiendo en él diversas tipologías de sujetos, tales como: migrantes, inmigrantes, turistas, residentes, transeúntes, refugiados, asilados, exiliados, entre otras (Brandariz García 201 1, 6; Wagman 2005, 83; Aebi 2008, 52 y ss.; García España 2001, 137 y ss.). Por ello, se hace necesaria una precisión terminológica, la que se decanta por comprender al sujeto pasivo no sólo como un extranjero, sino también y subyugado al mismo concepto, como migrante. Situación incuestionable por su también mención expresa, y que se posiciona como primer paso en un proceso interpretativo que respeta el principio de legalidad.

Las razones de una interpretación en ese sentido encuentran cabida en el derecho internacional y más concretamente en el pacto internacional que le dio origen a este ilícito penal, el cual permite establecer inequívocamente que el inmigrante es el sujeto pasivo. Así, la Convención de Palermo y particularmente su Protocolo complementario Contra el Tráfico Ilícito de Migrantes por Tierra, Mar y Aire, como su propio nombre indi-

ingresa a España o Chile en plan turista o incluso a cometer un delito, en forma clandestina o fraudulenta, unida a otros elementos típicos, podría ser considerado sujeto pasivo del delito en cuestión, en circunstancias que estimo que no lo es y no lo puede ser.

32 Véase el artículo 10 de la Constitución Política de la República de Chile, la carta fundamental chilena que define quienes son chilenos: "Los nacidos en territorio chileno (salvo excepciones); por derecho de sangre, los nacidos en el extranjero que sean hijos de padre o madre chilenos; los extranjeros que obtuvieran la nacionalidad chilena, y finalmente los extranjeros que obtuvieran por ley la nacionalidad por gracia".

33 Para Monclús Masó (2008, 27), la voz extranjero remite al concepto de Estado y de soberanía, porque es el Estado, en uso de su soberanía, el que atribuye la condición de nacional a unas personas, con exclusión de todo el resto, que son considerados extranjeros. 
ca, manifiesta la necesidad de luchar justamente contra el tráfico ilegal de migrantes, situando a este sujeto como víctima del delito. ${ }^{34}$

Una vez asentado que el sujeto pasivo del delito está referido a un extranjero migrante, queda por resolver qué se debe entender por migrante al no estar este concepto definido por la ley ni por los instrumentos internacionales que le sirven de fuente. La noción de migrante - bastante utilizada en diversas monografías y artículos sobre la materia - es definida por el Diccionario de la RAE como el "Que migra o emigra". Por su parte, migrar es sinónimo de "emigrar" 35 e "inmigrar", ${ }^{36}$ respectivamente; referido el primero, en su primera acepción, a: "Dicho de una persona, de una familia o de un pueblo: Dejar o abandonar su propio país con ánimo de establecerse en otro extranjero", y el segundo a: "Dicho del natural de un país: Llegar a otro para establecerse en él, especialmente con idea de formar nuevas colonias o domiciliarse en las ya formadas".

Tras la diferenciación que acabo de evidenciar, la expresión migrante también es genérica, abarca las especies inmigrar (llegar a un país) y emigrar (abandonar el país) respectivamente. Por lo tanto, se puede concluir que en el tipo penal de tráfico la noción migrante adolece de una latente heterogeneidad la cual puede generar dudas al referirse a dos sujetos que corren en direcciones opuestas o incluso antagónicas. En consideración a aquello, la noción apropiada para definir al sujeto es la de "inmigrante" (el cual además debe ser extranjero [diferenciar la inmigración interna] no residente en el país). En ella se designa exclusivamente a la persona

34 Además, entrega un concepto sobre lo que se debe entender por ese tráfico, indicando que "se entenderá la facilitación de la entrada ilegal de una persona a un Estado parte del cual dicha persona no sea nacional o residente permanente con el fin de obtener, directa o indirectamente, un beneficio financiero u otro beneficio de orden material".

35 La expresión emigrar, conforme al Diccionario de la RAE, tiene cuatro acepciones: 1. intr. Dicho de una persona, de una familia o de un pueblo: Dejar o abandonar su propio país con ánimo de establecerse en otro extranjero; 2. intr. Ausentarse temporalmente del propio país para hacer en otro determinadas faenas; 3. intr. Abandonar la residencia habitual dentro del propio país, en busca de mejores medios de vida; 4. intr. Dicho de algunas especies animales: Cambiar periódicamente de clima o localidad por exigencias de la alimentación o de la reproducción (Real Academia Española 2018).

36 La expresión inmigrar tiene dos acepciones, conforme al Diccionario de la RAE: 1. intr. Dicho del natural de un país: Llegar a otro para establecerse en él, especialmente con idea de formar nuevas colonias o domiciliarse en las ya formadas; 2. intr. Dicho de un animal: Instalarse en un territorio distinto del suyo originario (Real Academia Española 2018). 
de un país, que viene a otro para establecerse ahí y desarrollar su personalidad, entendiéndose por tal la realización de una vida familiar, social, económica, religiosa, etcétera (García España 2001, 138). Desde la óptica geopolítica, esta inmigración que se denomina externa o internacional es la que se ocupa del delito de tráfico (García España, 139).

En este concepto de inmigración menos heterogéneo y más restringido, caben tanto los extranjeros regulares como los irregulares - o ilegales-. Son irregulares o ilegales los que ingresan de manera clandestina (paso fronterizo no habilitado) o fraudulenta (documentación falsa); o permanecen en él una vez vencido el permiso de estancia o residencia; se les ha denominado extranjeros o inmigrantes ilegales o clandestinos o irregulares o peyorativamente los "sin papeles” (Monclús Masó 2008, 31).

La diferencia entre los términos inmigrante y extranjero, viene dada porque el primero es un sujeto que deja su país de origen para desarrollar su personalidad en otro país, en cambio el segundo si bien lo puede hacer con esa intención, también lo puede hacer con un propósito distinto, como sería el turístico, de negocios, o incluso con una finalidad criminal. Dicho de otra forma, lo que caracteriza al inmigrante es su proceso objetivo-subjetivo de migración; siendo el primero la intención de residencia - temporal o permanente - en el país de recepción (García España 2001, 140), y el segundo una motivación de desarrollarse social y económicamente en este nuevo país, para la supervivencia personal y familiar. ${ }^{37}$

Además del inmigrante como sujeto pasivo del delito, también la sociedad, en forma mediata, se puede consolidar como sujeto pasivo del delito cuando se produce la inmigración ilegal que es lo que el ilícito pretende evitar.

A modo de conclusión preliminar, el bien jurídico sistema migratorio, conforme a su propia naturaleza jurídica, sólo puede reconocer como sujeto pasivo al Estado, prescindiendo de la noción de extranjero o migrante, salvo para configurar el tipo (infringir la prohibición de su ingreso). A su vez, el rendimiento que entregan los bienes jurídicos denominados derechos de los ciudadanos extranjeros y orden público, implican respectivamente, entre otras cosas, reconocer como víctima a un extranjero, el

37 El concepto de inmigración económica se contrapone, desde el punto de vista del objeto y las causas, a la inmigración generada por los exiliados políticos. 
que además debe ser inmigrante y, por otro lado, evidenciar que potencialmente lo podría llegar a ser la sociedad en su conjunto.

\section{LOS VERBOS REGTORES DE LA CONDUGTA PUNIBLE}

El legislador español en un comienzo adoptó los verbos rectores promover, favorecer o facilitar, los que actualmente contempla el legislador chileno de cierta forma. ${ }^{38}$ Sin embargo, abandonó esa fórmula por ser amplia e imprecisa (Pomares Cintas 2015, 14; véase también Martínez-Buján Pérez 2016, 501), y la sustituyó por la prevista en el artículo 1.1. a) de la Directiva 2002/90/CE, que promueve el verbo "ayudar" (Villacampa Estiarte 2016, 752). Este se define como prestar cooperación intencionada a un no nacional de la Unión Europea a entrar o circular en territorio español de un modo que vulnere la legislación sobre entrada o tránsito de extranjeros (Pomares Cintas 2015, 15), y se ha indicado que este concepto no tiene ninguna dificultad conceptual (Lafont Nicuesa s. d., 11). Asimismo, se incrimina la ayuda intencionada para permanecer en territorio español cuando concurra ánimo de lucro, vulnerando también la legislación sobre extranjería (Villacampa Estiarte, 757). Conforme al Diccionario de la lengua española, ayudar implica "prestar cooperación, auxiliar, poner los medios para el logro de algo". Esto significa que la acción colaborativa debe ser idónea para posibilitar que el extranjero vulnere la legislación sobre entrada, tránsito y permanencia (Pomares Cintas, 15). Con esta modificación además de transformar la naturaleza del delito a uno de resultado material, ${ }^{39}$ se sigue castigando conductas que son claramente de complicidad (Martínez-Buján Pérez, 501; Villacampa Estiarte, 758).

STS núm. 536/2016, del 17 de junio: "Lo que se sanciona es la ayuda intencionada a la entrada o tránsito en territorio español de los inmigrantes ajenos a la Unión Europea, con vulneración de la normativa legal reguladora, así como a su permanencia en nuestro territorio, en este caso solamente cuando la conducta se realice con ánimo de lucro...".

38 Estos verbos rectores son originarios de la Ley Orgánica 4/2000, del 11 de enero, y se mantienen hasta la reforma de 2015 en que son derogados.

39 Alguna doctrina sostiene que se trata de un delito permanente (Queralt Jiménez 2015, 885). 
A su vez, el legislador chileno construye el tipo penal con base en dos verbos rectores: "promover" y "facilitar". Los que han sido interpretados, generalmente, conforme al significado que les reconoce el Diccionario de la Real Academia de la Lengua Española. ${ }^{40}$ Así, promover se define como "iniciar o adelantar una cosa procurando su logro o tomar la iniciativa para la realización o logro de algo, y facilitar consiste en hacer fácil o posible la ejecución de una cosa o la consecución de un fin" (Real Academia Española 2018). No huelga indicar que es la misma interpretación que se ha otorgado en otras figuras penales en que el legislador ocupa semejantes verbos rectores, como ocurre a propósito del delito de favorecimiento de la prostitución. ${ }^{41}$

Estos verbos deben ser entendidos en su sentido natural y obvio, es decir, la facilitación debe hacer posible la consecución de la entrada ilegal al país, y la promoción debe procurar que el extranjero tome la propia iniciativa para la realización de esa entrada ilegal. Ese es el sentido que le ha atribuido mayoritariamente la jurisprudencia. ${ }^{42}$

STOP de Santa Cruz 67/2012, del 12 de marzo de 2013: “...de que efectivamente el acusado facilitó, en el sentido de que cooperó y posibilitó activamente, y también promovió, en cuanto incitó y tomó la iniciativa

40 También alguna doctrina existente tiene una concepción amplia de estos verbos, resumido en ciertas formas de tomar la iniciativa en determinar a otro a ingresar ilegalmente al país o cooperar en esta iniciativa (Mardones y Fernández 2011, 14 y ss.).

41 Garrido Montt (2007, 308), a propósito del delito de promoción de la prostitución, que utiliza los mismos verbos rectores que el delito que estamos analizando, entiende el verbo facilitar como posibilitar el ejercicio de algo, como sería mediante la proporción de los medios para alcanzar un determinado cometido; a su vez comprende el vocablo promoción como inducir o inclinar a otros hacia un fin determinado. Por su parte, Politoff, Matus Acuña y Ramírez $(2007,283)$ en su conocido manual, a propósito del mismo delito sexual, sin hacer mayores disquisiciones hacen sinónimas las locuciones de promoción y facilitación, señalando que significa incitar o mantener lo ya iniciado (véase también Etcheberry 2010, 78). A su vez, el proyecto de ley que modifica el Código Penal, año 2014, abandona el término promoción y se queda sólo con el de facilitar, el que tampoco es definido por el legislador. Consúltese el artículo 502 del Proyecto de Código Penal de 2014; el delito de favorecimiento de la prostitución está previsto en el artículo 367 del código penal chileno.

42 Cuarto Tribunal Oral en lo Penal de Santiago, sentencia del 13 de diciembre de 2012, RUC 1001114184-1; Tribunal Oral en lo Penal de Santa Cruz, sentencia del 12 de marzo de 2013, RUC 1200236968-9; Tribunal del Juicio Oral en Lo Penal de Arica, sentencia del 20 de noviembre de 2013, RUG 1300331670-4; Tribunal Oral en lo Penal de Santa Cruz, sentencia del 8 de junio de 2015, RUC $1110028038-K$.

Esta obra está bajo una Licencia Creative Commons

Atribución-NoComercial-SinDerivar 4.0 Internacional, IIJ-UNAM.

Boletín Mexicano de Derecho Comparado, núm. 155, mayo-agosto de 2019, pp. 1015-1045. 
para conseguirlo, el ingreso al país de los 43 ciudadanos peruanos indicados en la acusación".

En consideración a los verbos rectores, el delito en Chile sanciona, entre otras, conductas de consumación anticipada, en que no es importante o necesario que se llegue a producir un efectivo traspaso de las fronteras para la consumación del delito, ${ }^{43}$ sino que basta con una ayuda encaminada a dicho logro, como sería por ejemplo una labor de captación de extranjeros. ${ }^{44}$ Respecto de la precisión que debe tener esa colaboración para que sea penalmente relevante, se debe tratar de una conducta orientada a que el extranjero ingrese de manera ilegal al país. Así, por ejemplo, el captador será penalmente responsable cuando sabiendo, incita a un extranjero a que ingrese al país por un paso fronterizo no habilitado o de una forma poco segura para su integridad (transitar por una montaña escarpada, viajar en el estanque de bencina de un vehículo, introducido en un tambor, etcétera), todo acompañado del especial elemento subjetivo del tipo (ánimo de lucro). Pero no basta con una simple ayuda o colaboración, sino que ella debe redundar en actos que de manera directa sirvan para alcanzar el cometido del ingreso ilegal al país. Si bien no se trata de un elemento explícitamente contenido en la norma, sí se infiere de aquella, a propósito de sus verbos rectores, dado que ambos suponen la consecución de un fin, que no es otro que, el ingreso ilegal al país. La promoción ocurre a nivel de fuero interno de la víctima, que resuelve voluntariamente el ingreso ilegal, y la facilitación de forma externa que se produce con la entrega de medios idóneos para alcanzar el fin de poder ingresar al país. Dicho de otro modo, las conductas que son funcionales deben estar dirigidas — como finalidad - al ingreso ilegal al país.

Siguiendo con el caso chileno, actividades indirectas, como las de dar alojamiento o comida en faenas de tráfico implican conductas de favorecimiento, pero no de facilitación, y por ello pareciera descartarse su punición bajo el delito en comento. En efecto, el favorecimiento es una

43 Alguna doctrina chilena considera que se trata de un delito de resultado, el cual se consuma cuando se produce el ingreso ilegal al país, siendo frustrado cuando la detención se realiza antes del traspaso de las fronteras, y finalmente hay tentativa cuando el sujeto ha dado comienzo a la ejecución de los actos de promoción o facilitación, pero falta todavía uno o más para que el inmigrante esté en condiciones de traspasar ilegalmente las fronteras (Matus Acuña y Ramírez 2014, 201).

44 Cuestión aparte son los problemas de jurisdicción que de ello puedan derivar. 
locución más amplia que la facilitación y conlleva, en general, acciones de ayuda o apoyo para el tráfico (la facilitación es una modalidad de favorecimiento, pero no es necesariamente un favorecimiento en el sentido estricto de la expresión). La atipicidad de las conductas descritas se fundaría en que, más allá de los motivos altruistas que puedan implicar, el concepto "facilitar" no abarcaría tales acciones al no tratarse de conductas que harían posible, de manera directa, la consecución del fin previsto en la norma penal como es la entrada ilegal al país. ${ }^{45}$ Lo anterior no obsta, a que la participación en dicha forma pueda castigarse como complicidad.

Ahora, tratándose del delito en comento, en España, la situación de conductas indirectas no sigue la misma suerte, ya que semánticamente el verbo ayudar es más amplio y dichas conductas podrían ser subsumidas.

La otra diferencia es que en la legislación chilena sólo se sancionan las acciones que necesariamente están encaminadas a asegurar el ingreso al país y no a permitir la permanencia en él. A su vez, en el caso español el ámbito de aplicación es más amplio porque las acciones no sólo van dirigidas al ingreso, sino también a la permanencia en España o el tránsito hacia otro Estado.

\section{CONCLUSIÓN}

El rendimiento que entrega el bien jurídico denominado interés en controlar los flujos migratorios para legitimar el delito de tráfico de migrantes es insuficiente. Por su penalidad, en España - hoy - se puede hacer la vista gorda a su respecto, pero en Chile la consecuencia penal no guarda proporcionalidad con su lesividad. Sin perjuicio que, en ambos casos, transgrede abiertamente el principio de subsidiariedad penal.

Tampoco se puede dejar de advertir que en el caso español el delito de tráfico de migrantes se configura como una mera infracción administrativa que importa una vulneración simple, lisa y llana del control de los flujos migratorios como principal interés social. En cambio, en el caso chileno la situación es más compleja, pues se trata de un delito que requiere más

45 España, previo a la modificación del Código Penal, ocurrida en 2015, además de los verbos reconocidos en nuestra legislación, contemplaba el término favorecer. Con la modificación impetrada por la LO 1/2015, del 30 de marzo, el delito de tráfico de migrantes previsto en el artículo 318 bis, sólo utiliza el verbo rector "ayudar". 
que una simple infracción a una norma administrativa. Se precisa, además, una conducta que sea idónea para poner en riesgo los derechos de los ciudadanos extranjeros - inmigrantes - y el orden público.

El sujeto pasivo en España, a la luz del interés social que protege la norma penal, es el Estado y no el extranjero. Éste último se configura como objeto del delito, el que sólo puede ser una persona que no sea nacional de un Estado miembro de la Unión Europea, porque su entrada o permanencia en España debe vulnerar la legislación administrativa (entrada, tránsito o estancias de extranjeros). A su vez, en Chile el sujeto pasivo debe ser interpretado restrictivamente y reducido solamente a un inmigrante inserto en un proceso migratorio y no un simple extranjero.

Para terminar, el verbo rector "ayudar" utilizado para el tipo penal en España, vino a superar los inconvenientes interpretativos suscitados por los verbos actualmente regulados por el legislador chileno que se posicionan en conductas muy acotadas.

\section{REFERENCIAS BIBLIOGRÁFICAS}

AeBI, Marcelo F. 2008. Temas de Criminología. Madrid: Dykinson.

AMNiSTÍA INTERNACIONAL. s. d., última consulta: 28 de septiembre de 2019. https://wwre.es.amnesty.org/temas/refugio-e-inmigracion/sos-europe-mi gracion-y-refugio-en-europa/victimas-en-el-mediterraneo/.

ANTÓn Morales, José Antonio. 2011. Criminalidad versus criminalización de la inmigración en España: La eficacia policial en el control de fronteras. Ley de extranjería y Derechos Humanos. España: Editorial Académica Española.

Biblioteca del Gongreso Nacional de Chile. 2011. Historia de la Ley núm.20.507,http://wwrw.leychile.cl/Navegar/scripts/obtienearchivo?id=recursos legales/10221.3/35003/1/HL20507.pdf.

BILES, Eleanor. 2014. "Papa pide a Europa impedir que Mediterráneo sea cementerio de inmigrantes". Reuters. 25 de noviembre. https://es.reuters. com/article/entertainmentNews/idESKCNOJ91HD20141125.

BRANDARIZ GARCía, José Ángel. 2011. Sistema penal y control de los migrantes: Gramática del migrante como infractor penal. Granada: Comares.

Garnevali Rodríguez, Raúl. 2017. Propuesta de redacción Delitos de tráfico ilícito de personas y trata de personas. Manuscrito no publicado. 
DAL LAGO, Alessandro. 2006. "Esistono davvero i conflitti tra culture?" En Multiculturalismo: Ideologie e sfide, ed. Carlo Galli. Bolonia: Il Mulino, 2006.

Daunis Rodríguez, Alberto. 2009. El Derecho penal como herramienta de la política migratoria. Granada: Comares.

DAUnis RoDríGueZ, Alberto. 2013. El delito de trata de seres humanos: El artículo 177 BIS CP. Valencia: Tirant lo Blanch.

DAUnis RODRÍGUEZ, Alberto. 2017. "La inmigración ante la encrucijada: El tráfico ilegal de personas, la trata de seres humanos y la explotación sexual." En Criminalidad organizada transnacional: Una amenaza a la seguridad de los estados democráticos, Laura Zúñiga Rodríguez (dir.), Julio Ballesteros Sánchez (coord.). Valencia: Tirant lo Blanch.

De León Villalba, Francisco Javier. 2003. Tráfico de personas e inmigración ilegal. Valencia: Tirant lo Blanch.

Díaz y García Conlledo, Miguel (dir.). 2007. Protección y expulsión de extranjeros en derecho penal. Madrid: La Ley.

Etcheberry, Alfredo. 2010. Tomo IV de Derecho penal: Parte especial, 3a. ed. Santiago: Editorial Jurídica de Chile.

Gajardo Orellana, Tania, y Torres Figueroa, Antonia. 2011. "Los tipos penales del tráfico de migrantes y trata de personas en la ley 20.507”. Revista Furídica del Ministerio Público 47: 231-251.

García EsPaña, Elisa, y RodríGuez CAndela, José Luis. 2002. "Delitos contra los derechos de los extranjeros (artículo 318 bis del Código Penal)". Actualidad Penal 29: 723-751.

García EsPaÑA, Elisa. 2001. Inmigración y delincuencia en España: Análisis criminológico. Valencia: Tirant lo Blanch.

Garrido MontT, Mario. 2007. Tomo III de Derecho penal: Parte especial, 3a. ed., Santiago: Editorial Jurídica de Chile.

Gómez LóPEz, María Isabel, y Muñoz Sánchez, Esther. 2017. "Algunas cuestiones en torno al delito de trata de seres humanos en el ordenamiento jurídico español." Cuadernos de política criminal 123 (III, Época II): 213-246.

IGLESIAS Skulj, Agustina. 2015. "Artículo 318 Bis: Delitos contra los ciudadanos extranjeros." En Comentarios a la reforma del código penal de 2015, 2a. ed. González Cussac, José Luis (dir.), Gorriz Royo, Elena y Matallín Evangelio, Ángela (coords.). Valencia: Tirant lo Blanch. 
Instituto Nacional de Derechos Humanos de Chile. 2017. Informe Anual 2017. Situación de los Derechos Humanos en Chile. Santiago de Chile: INDH.

LAFONT Nicuesa, Luis. s. d. "La protección jurídica penal de los inmigrantes y trabajadores extranjeros". Ponencias de Formación Continuada, Centro de Estudios Jurídicos, Fiscalía General del Estado. La Coruña, España.

Laurenzo Copello, Patricia. 2003. "La protección penal de los derechos de los ciudadanos extranjeros." Revista de Derecho Penaly Criminología 12: 63-93.

Maldonado Fuentes, Francisco. 2012. "Acceso a la justicia”. Seminario internacional sobre trata de personas y tráfico de migrantes. Santiago: INDH.

MANERI, Marcello. 2010. "Los medios de comunicaciones y la guerra contra las migraciones." En Criminalización racista de los migrantes en Europa, PALIDDA, Salvatore y BRANDARIz García, José Ángel (dir.). Granada: Comares.

MARdones, Fernando y Fernández, José Manuel. 2011. "Ley 20.507, tipifica el tráfico de inmigrantes y trata de personas". Departamento de Estudios de la Defensoría Nacional 5. http://wrere.biblio.dpp.cl/biblio/DataFiles 15734-2.pdf

Martínez-Buján Pérez, Carlos. 2016. "Delitos contra los derechos de los ciudadanos extranjeros". Derecho penal: Parte especial, 5a. ed., GONZÁLez Cussac, José Luis (coord.). Valencia: Tirant lo Blanch.

Matus Acuña, Jean Pierre, y Ramírez, María Cecilia. 2014. Lecciones de derecho penal chileno: Parte especial, 3a. ed. Santiago: Thomson Reuters.

MATUS ACUÑA, Jean Pierre. 2011. "Sobre la necesidad de la existencia de un bien jurídico a proteger por los tipos penales". Derecho penal, criminología y política criminal en el cambio de siglo. Santiago: Editorial Jurídica de Chile.

MONCLÚs MASÓ, Marta. 2008. La gestión penal de la inmigración: El recurso al sistema penal para el control de los flujos migratorios. Buenos Aires: Editorial del Puerto.

Monge Fernández, Antonia. 2017. "Reflexiones críticas sobre el delito de trata de seres humanos tras la reforma penal de 2015". Cuadernos de política criminal 121 (I, Época II): 17-70.

Muñoz Conde, Francisco. 2015. Derecho penal: Parte especial, 20a. ed. Valencia: Tirant lo Blanch.

Muñoz Conde, Francisco. 2017. Derecho penal: Parte especial, 21a. ed. Valencia: Tirant lo Blanch. 
Navarro Cardoso, Fernando. 2006. "Extranjería, inmigración y sistema penal." En Inmigración y sistema penal: Retos y desafios para el siglo, 21 a. ed., Rodríguez Mesa, María José y Ruíz Rodríguez, Luis Ramón (coords.). Valencia: Tirant lo Blanch.

Ortubay Fuentes, Miren. 2002. "El impreciso concepto de tráfico ilícito de personas o la mentalidad de fortaleza sitiada". En ECHANO BASALDÚA, Juan (coord.). Estudios jurídicos en memoria de fosé María Lidón, España: Universidad de Deusto.

PÉrez Alonso, Esteban Juan. 2008. Tráfico de personas e inmigración clandestina. Valencia: Tirant lo Blanch.

Politoff L., Sergio, Jean Pierre Matus A y María Cecilia Ramírez G. 2007. Lecciones de derecho penal chileno: Parte especial, 2.a ed. Santiago: Editorial Jurídica de Chile.

Pomares Cintas, Esther. 2015. "Reforma del Código Penal Español en torno al delito de tráfico ilegal de migrantes como instrumento de lucha contra la inmigración ilegal en la unión europea." Revista de Estudios Jurídicos UNESP 19 (29).

Queralt JimÉnez, Joan (dir.) 2015. “Delito asociado: Tráfico ilegal de ciudadanos extranjeros" En Derecho penal español: Parte especial. Valencia: Tirant lo Blanch.

Ribas Mateos, Natalia. 2002. El debate sobre la globalización. Barcelona: Bellaterra.

Rodríguez Mesa, María José. 2001. Delitos contra los Derechos de los ciudadanos extranjeros. Valencia: Tirant lo Blanch.

Rodríguez MONTAÑÉS, Teresa. 2001. "Ley de extranjería y derecho penal". La Ley 2: 1736-1743.

Roxin, Claus. 2007. Derecho penal: parte general. Fundamentos, la estructura de la teoría del delito. 2a. ed., trad. de Diego Luzón Peña, España: Civitas Ediciones. t. I.

Santana Vega, Dulce. 2015. "Título XV Bis, Delitos contra los derechos de los ciudadanos extranjeros". En Comentarios al Código penal Reforma LO 1/2015 Lo 2/2015, Corcoy Bidasolo, Mirentxu (dir.) y Mir Puis, Santiago. Valencia: Tirant lo Blanch.

Serrano-Piedecasas, José Ramón. 2002. "Los delitos contra los derechos de los ciudadanos extranjeros". En Laurenzo Copello, Patricia (coord.). Inmigración y derecho penal: Bases para un debate, Valencia: Tirant lo Blanch.

Esta obra está bajo una Licencia Creative Commons

Atribución-NoComercial-SinDerivar 4.0 Internacional, IIJ-UNAM.

Boletín Mexicano de Derecho Comparado, núm. 155, mayo-agosto de 2019, pp. 1015-1045. 
Soto Donoso, Francisco. 2009. "Aspectos dogmáticos del delito de trata de personas del artículo 3o. del Protocolo de Palermo". Revista Furídica del Ministerio Público 39.

Villacampa Estiarte, Carolina. 2011. "Comentario Artículo 177 bis". En Comentarios a la parte especial del derecho penal, Quintero Olivares, Gonzalo (dir.). Navarra: Editorial Aranzadi.

Villacampa Estiarte, Carolina. 2016. "Delitos contra los derechos de los ciudadanos extranjeros, artículo 318 bis". En Quintero Olivares, Gonzalo (dir.), Morales Prats, Fermín. Comentarios al código penal español, tomo II, 7a. ed., Navarra: Editorial Aranzadi.

Wagman, Daniel. 2002. "Estadística, delito e inmigrantes". Biblioteca Ciudades para un Futuro más Sostenible 21. http://habitat.aq.upm.es/boletin/n21/ adwag.html/.

Wagman, Daniel. 2005. "Población extranjera y minorías étnicas". En César Manzanos (coord.). Servicios sociales y cárcel. Alternativas a la actual cultura punitiva, Vitoria-Gasteiz: Salhaketa. 